\title{
RAILWAY WHEEL AND RAIL ROUGHNESS ANALYSIS
}

The paper deals with the railway wheel unroundness (out-of-round) analysis and with the rail head roughness analysis. Roughness of the running surfaces is the predominant source of noise of rail bound transport systems today. Reliable measurements of the roughness of rails and wheels are crucial for noise reduction purposes. In the past, the main purpose of measurements was the understanding of corrugation growth and rolling noise generation. Meanwhile, quantitative descriptions have gained considerable importance.

Key words: out-of-round, rail roughness, butterfly method, one-third octave analysis

\section{Introduction}

In general, wherever the rolling of one body surface over another body surface occurs, there the noise is generated. In the case when the surfaces of bodies which are in contact are smooth enough or if the rolling is slow enough, the level of the noise may be so low as if the rolling were noiseless. The noise which is conducted through the air is not caused only by rolling. Rolling members and the track surface on which the rolling occurs cause vibrations different from those which are responsible for the noise which is led through the air. They might be expressed in two ways. On one side are vibrations and noise in a vehicle supported by rotating members (wheels). This noise may be a component of a big part of vibrations which go through suspensions and construction of the vehicle and occur in the vehicle body as a repeatedly emitted noise. This increases the noise coming more directly through the air. On the other hand, the vibrations, which are generated on the track surface, on which the wheels roll, might be transmitted into and through the construction and the subsoil which support them.

\section{Noise and vibration sources}

The accompanying phenomenon of whichever transport system operation is noise and vibrations. The railway operation is not an exception. The generated noise very often reaches such a level of parameters which is not possible, from the point of view of surroundings in which the railway is situated, to be ignored or its negative influence cannot be underestimated. The main parameters which have the influence on the noise level are the following ones [3]:

The temperature of the rail may change in accordance to the air temperature as a result of thermal radiation it may have an
Parameters which have influence on the noise level

Tab. 1

Rail type Distance of internal wheels faces

Static stiffness of the subsoil Track gauge

Quotient of subsoil damping Wheels tread surface roughness

Sleepers type

Roughness of not corrugated rail head surface

Distance of sleepers Velocity of a train

Gravel ballast stiffness Wheel force

Quotient of the gravel ballast damping Air temperature

influence on the temperature of subsoil and on the stiffness and damping of subsoil.

The European norm prEN ISO 3095 [5] specifies conditions for the obtaining of results which are to be described and compared. The results concern the level and spectrum of noise which is emitted by all kinds of vehicles which operate on tracks or other types of rigid track with the exception of track maintenance machines in operation.

The results might be used for the characteristics of noise emitted by these vehicles during type and inspections tests and for the comparison of noise emissions of various vehicle types on specific parts of a track.

In accordance to the presented issues in the following text, the emphasis will be placed on the wheel un-roundness and rail unevenness. The noise which occurs as a result of rolling (and others processes) is characterised with the help of its level and spectrum.

\footnotetext{
* Tomas Lack, Juraj Gerlici

Faculty of Mechanical Engineering. University of Zilina, Zilina, Slovakia, E-mail: tomas.lack@fstroj.uniza.sk
} 
The noise level caused by the rolling: in general there are two known parameters which have a direct influence on the noise level when rolling:

- faster process of rolling, higher level of noise,

- more rough surface in contact, higher level of noise.

In the case of railway wheel rolling over the rail, the influence of surface roughness of bodies in contact is mainly expressed.

\section{Roughness of the rail head surface}

The most prominent cause of higher roughness is a corrugated or waved track, which was created in the longitudinal direction during the railway operation.

The influenced place on the rail is very often irregular, its length may change from several tens of millimetres up to hundreds of millimetres and the maximum depth of the groove reaches tens of microns.

When the surface of the rail is smooth (where the depth of the groove is smaller than 10 microns), roughness of surfaces participates only in a small extent in the overall level of noise, which is determined mainly by the type of vehicles in operation. When the level of wrinkles is very low, the surrounding noise (measured in a distance of $25 \mathrm{~m}$ from the track) of vehicles which are braked by the block brake [5] is higher than vehicles which are braked by the disc brake at about $10 \mathrm{~dB}$.

The level of noise when increasing the level of wrinkles for disc brakes increases faster than for the vehicles with block brakes. When the wrinkles of track reach a certain value from the point of view of noise level, there is no difference between separate types of vehicles. So far there have not been efforts for the quantification of critical wrinkles. Wrinkles occur in many different forms and so far it has not been stated which form or which forms participate in the noise increase and to which extent.

Roughness is the root mean square value (RMS) of the rail running tread change size in the direction of the movement (longitudinal level) measured along the rail, expressed in $\mu \mathrm{m}$.

Level of the roughness is the level in $\mathrm{dB}$ determined by the following equation:

$$
L_{r}=20 \cdot \log \left(\frac{r}{r_{0}}\right)^{2} \quad \mathrm{~dB}
$$

where:

$L_{r}$ is the level of the roughness,

$r$ is root mean square roughness amplitude,

$\mathrm{r}_{0}=1 \mu \mathrm{m}$ is reference roughness.

When measuring the vehicle or train noise, the conditions which from the point of view of the rail head surface and vehicle wheels have to be met, offer an acceptable influenced final image of the complete evaluation of the vehicle noise. These conditions lay in the values quantification of rail head surface unevenness (and wheels) and in specification of limit values under which the measurement of noise is acceptable. (Notice: For conventional vehicles, the measurements should be performed on a gravel bed with wooden or concrete sleepers, the track should be dry and not frozen, well maintained, the level gradient at the track shall be 1:100 at the most in radii $\mathrm{R}=\min 3000 \mathrm{~m}$ for the velocity up to $120 \mathrm{~km} / \mathrm{h}$ and $\mathrm{R}=\min 5000 \mathrm{~m}$ for the velocity higher than $120 \mathrm{~km} / \mathrm{h}$, in the measured section welded (without transitional sections), and without visible surface defects (material accumulation (and a hole in material) which got between the wheel and rail during the operation and so on).

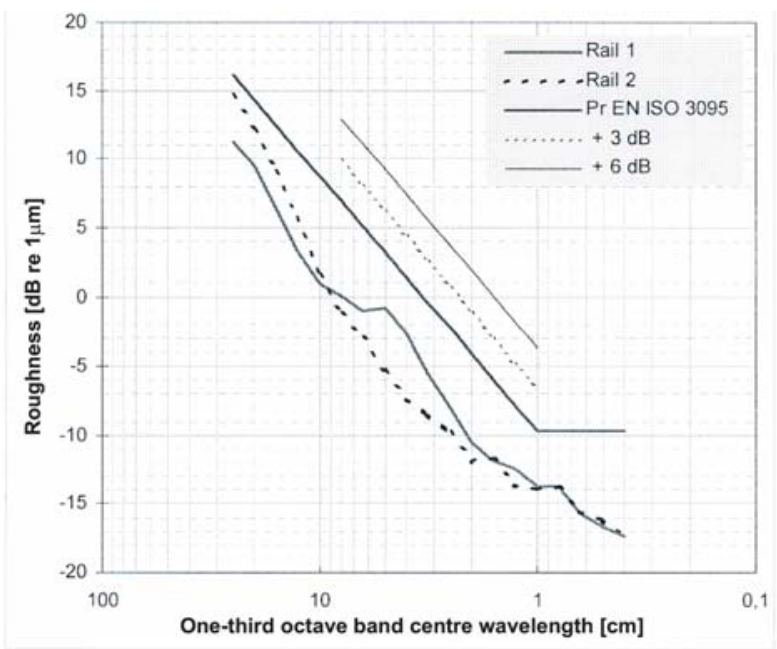

Fig. 1 The example of limit values of the rail surface roughness for high speed trains [1]

The quality of the rail head should be taken as accepted for measurements in the case when the surface roughness level of the tested track evaluated by the one third octave filter lays within the determined borders (Fig. 1).

Dynamic characteristics of the track have an important influence on the track contribution to the overall noise. Phenomena with the biggest influence on the noise are listed in Tab. 1. A real track may be characterised by measurements at static conditions on an unloaded track:

- vertical and horizontal railhead impedance (contains pad stiffness and damping),

- vertical and horizontal spatial decrease (includes the influence of subsoil and fasteners).

The impedance and decay are determined with the help of feedback measurement in the frequency domain $100 \mathrm{~Hz}-8000 \mathrm{~Hz}$. Notice: In order to determine a noise level range arising from the roughness the TWINS (Track Wheel Interaction Noise Software) programme is available at UIC [5]. As its input the programme used the diameter $+/-1$ of the standard roughness deviation. Because the noise from a smooth wheel is very sensitive to the changes of rail roughness, the predictions were done for the wheel 
which is braked by a disc brake and for the train velocity of $144 \mathrm{~km} / \mathrm{h}$.

The results of this analysis were utilised to determine the roughness influence on various noise levels from rolling so that it would be possible to elaborate recommendations for the roughness range which would be possible to be used as a standard for measurements processing.

Finally the results were elaborated into the recommendations for maximum roughness borders (limits) which define the track of "good quality" [5].

The results may be represented in one third octave belt with the roughness level of rail (in $\mathrm{dB}$ and reference of $1 \mu \mathrm{m}$ ) as a function of a wavelength $(\mathrm{cm})$

\section{Unroundness of the wheel}

The second member of the couple, which has an influence on the noise generation when rolling, is the railway wheel. The surface unevenness might be defined as a roughness deviation (differences between a real wheel radius and the ideal radius). It is possible to evaluate the unroundness in the plane of contact circles (seventy millimetres from the inner side of the wheel) or in plains which are parallel with it. In order to process the analysis, a numerical elaboration of measured data is necessary. The Fast Fourier Transformation (FFT) is the base of such an elaboration. We will mention the calculation procedure with the help of discrete Fourier Transformation (DFT) [4].

The measurement of wheel radius is done for separate angles of wheel semi-rolling $\alpha$. The Fourier analysis is applied on the set of measured data till we obtain the $R(\alpha)$ function.

$$
\begin{aligned}
& R(\alpha)=\sum_{k=0}^{L}\left[a_{k} \cdot \cos (k \cdot \alpha)+b_{k} \cdot \sin (k \cdot \alpha)\right], \\
& k=0,1,2, \ldots \mathrm{L} \\
& L=\frac{m}{2} \quad \text { interpolation } \\
& L<\frac{m}{2} \quad \text { approximation } \\
& a_{0}=\frac{1}{m+1} \cdot \sum_{s=0}^{m} R\left(\alpha_{s}\right) \\
& b_{0}=0 \\
& a_{k}=\frac{2}{m+1} \cdot \sum_{s=0}^{m} R\left(\alpha_{s}\right) \cdot \cos \left(k \cdot \alpha_{s}\right) \\
& b_{k}=\frac{2}{m+1} \cdot \sum_{s=0}^{m} R\left(\alpha_{s}\right) \cdot \sin \left(k \cdot \alpha_{s}\right) \\
& v_{k}=\operatorname{arctg} \frac{a_{k}}{b_{k}}, s=0,1, \ldots, m k=1,2, \ldots, L
\end{aligned}
$$

The coefficients of the order represent separate harmonic parts of oscillation. For practical reasons we use the Fast Fourier Transformation (FFT), which is crucially faster.

The Fast Fourier Transformation - FFT is another way of Fourier Transformation calculation. The algorithm of evaluation has the computation time:

Computation time $=k_{F F T} N \log _{2} N$, which is in comparison with the computation time of DFT

Computation time $=k_{D F T} N^{2}$ crucially shorter.

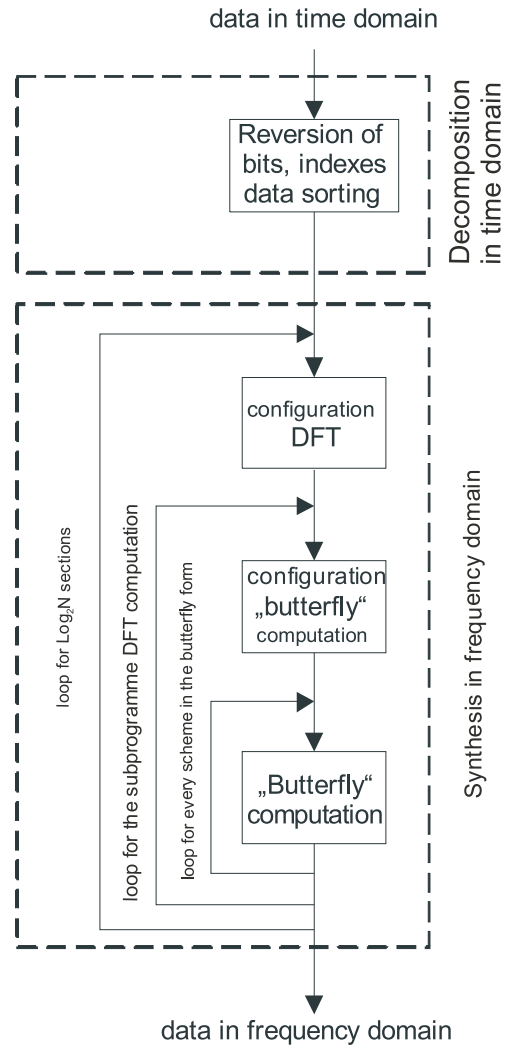

Fig. 2 Flowchart FFT

The flowchart depicts three essential steps: (1) to decompose $\mathrm{N}$ points in time domain into $\mathrm{N}$ signals out of which contains one point, (2) to find the signals spectrum of each point and (3) to make a synthesis of $\mathrm{N}$ frequency spectra into one frequency spectrum. The condition is that $\mathrm{N}$ must be a square of two.

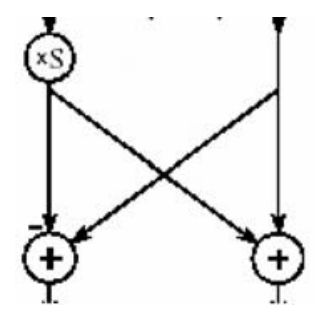

Fig.3 "Butterfly method computation of FFT" 


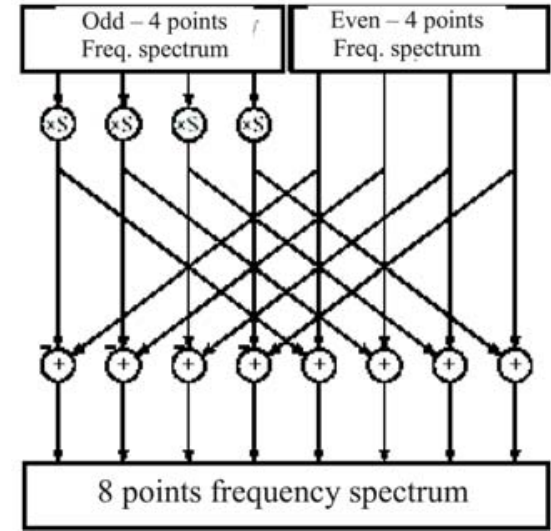

Fig. 4 The FFT synthesis flow chart

The basic calculation element in FFT which takes two complex points and converts them into two different complex points is depicted in Fig.3. This basic block diagram is called "Butterfly calculation", because of its image which reminds of butterfly wings. The flowchart of FFT synthesis depicts a method of combination of two four-point frequency spectra into one eight-point frequency spectrum. The symbol of operation " $\mathbf{X S}$ " means that the signal is multiplied by the sinus function with a suitably chosen frequency.
This example shows the procedure for $\mathrm{N}=8$ points. The signal depiction in the frequency domain allows us to have an idea about the measured signal features in the frequency domain. This depiction allows to configure numerical filters in the right way and to utilize only requested parts of the measured signal. At the same time it allows to discover some unwanted parts of the signal which may be caused by faulty condition of a part of the measurement system.

\section{Evaluation of wheel unroundness}

The base for the wheel unroundness evaluation is the knowledge of instant values of wheel radii dependence on the wheel semi-revolution angle.

In Fig. 5 the dependency of the instant value of the wheel radius in the range of angle extent from 0 to $2 \pi$ radian is depicted.

Amplitudes of separate harmonic parts characterise the geometrical shape of the measured wheel. The zero harmonic part represents the mean radius of the wheel. The first harmonic part determines eccentricity, the second one determines oval shape, the third one the degree of triangle shape, the fourth one the degree of rectangle, the fifth one the degree of pentangle and $n$-th one the degree of n-tangle.

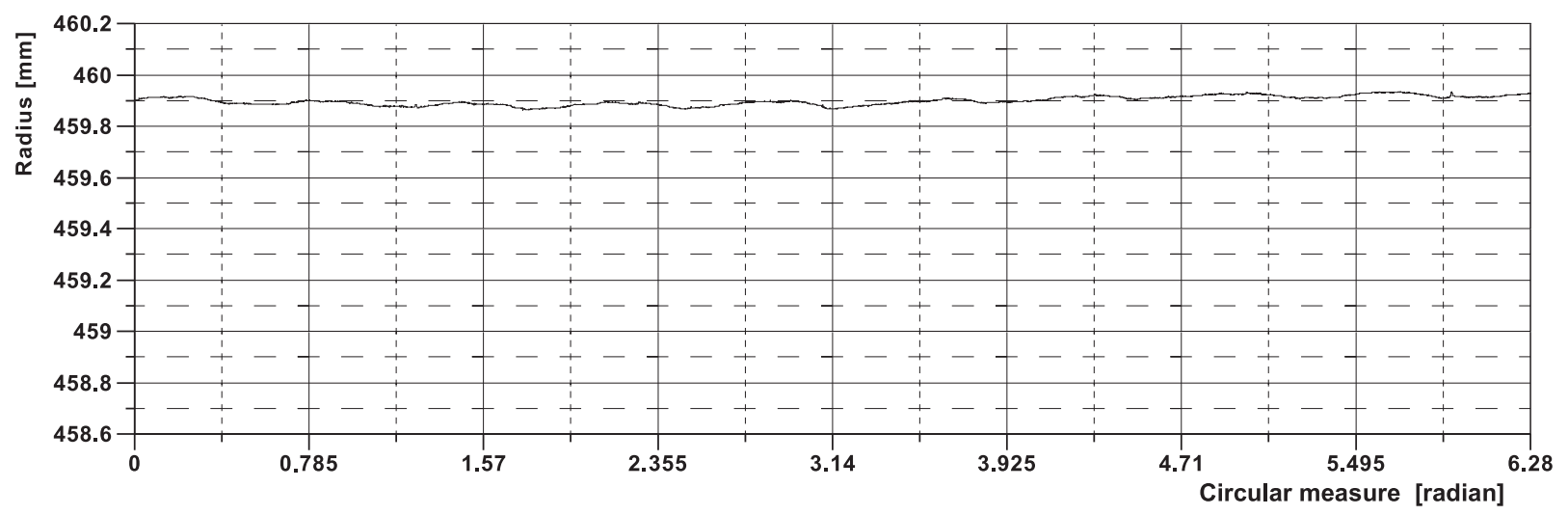

Fig. 5 Graph of wheel radii values

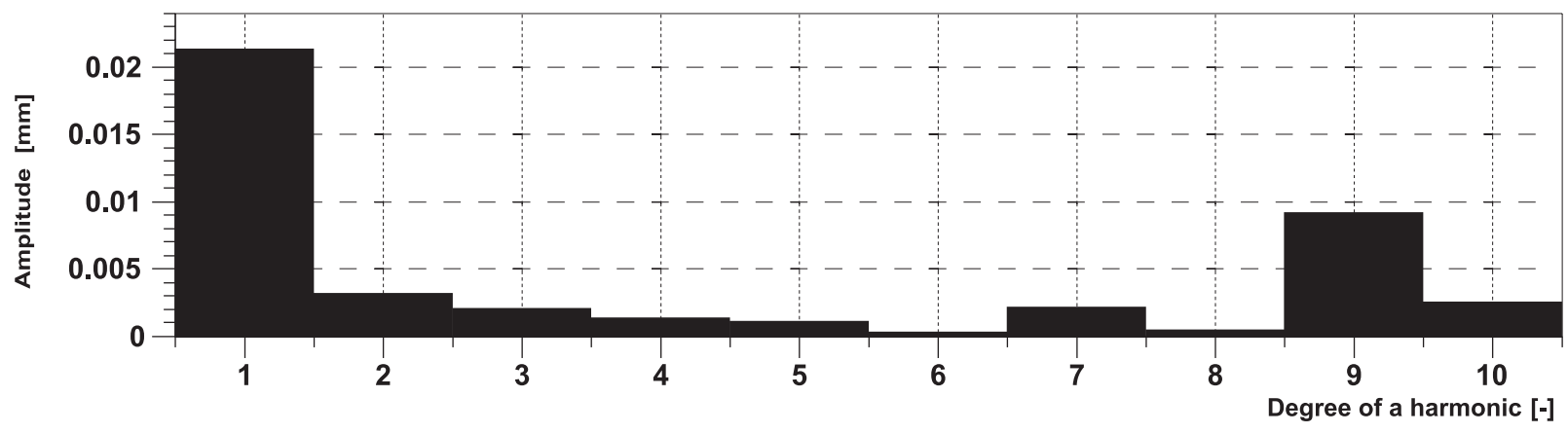

Fig. 6 Amplitude values of separate harmonic parts $1 \div 10$ diagram 


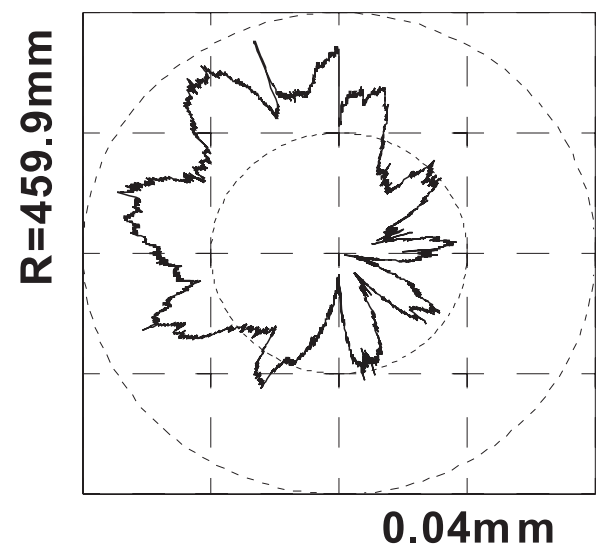

Fig. 7 Wheel radii values in the polar diagram

The ideal but hardly reachable state would occur when all parts except the zero one would be zero.

In Fig.7 the dependency of the instant value of the wheel radius in the range of angle extent from 0 to $2 \pi$ radian in polar diagram is depicted.

The mean wheel radius (the amplitude of the zero harmonic) represents the inner circle in the diagram. In this case it corresponds to the wheel with an average value of radius of $459.9 \mathrm{~mm}$. Another determining parameter of the graph is the outer circle with a double radius of the inner circle. In this case, the distance between the radii is $0.004 \mathrm{~mm}$.

\section{One third octave analysis}

The one third octave analysis is based on the Fast Fourier Transformation.

The algorithm of discrete or fast Fourier transformation is applied on the set of measured values. The sum of amplitudes in the range of the tierce is performed for individual parts of the signal. The frequency spectrum is divided into individual tierce on the base of marginal values.

Numerical borders divide the frequency range into octaves. The frequency range which represents octave is divided into tierces. In the framework of the octave third the sum of power spectra densities (PSD) is processed and the result is added to the representative of the octave third.

When evaluating the data in the form of graph, we depict the dependence of the sum PSD from the frequency in the decade, or logarithmic axis, or the amplitudes from the wavelength in the decade or logarithmic axis.

The wheels parameters are evaluated in one wheelset, taking into consideration the position of the wheels in the bogie (left side, right side), wheelset in the bogie, bogie in the vehicle, type of the
The marginal values of tierces and octaves

Tab. 2

\begin{tabular}{|c|c|c|c|c|c|c|}
\hline Middle & \multicolumn{3}{|c|}{ Tierce } & \multicolumn{3}{|c|}{ Octave } \\
\hline $\begin{array}{c}\mathrm{fm} \\
{[\mathrm{Hz}]}\end{array}$ & $\begin{array}{l}\text { f0-fu } \\
{[\mathrm{Hz}]}\end{array}$ & $\begin{array}{c}\mathrm{F} 0 \\
{[\mathrm{~Hz}]}\end{array}$ & $\begin{array}{c}\mathrm{fu} \\
{[\mathrm{Hz}]}\end{array}$ & $\begin{array}{l}\text { F0-fu } \\
{[\mathrm{Hz}]}\end{array}$ & $\begin{array}{c}\mathrm{F} 0 \\
{[\mathrm{~Hz}]}\end{array}$ & $\begin{array}{c}\mathrm{Fu} \\
{[\mathrm{Hz}]}\end{array}$ \\
\hline 20 & 5 & 22 & 18 & \multirow{3}{*}{22} & \multirow{3}{*}{45} & \multirow{3}{*}{22} \\
\hline 25 & 6 & 28 & 22 & & & \\
\hline 31.5 & 7 & 35 & 28 & & & \\
\hline 40 & 9 & 45 & 36 & \multirow{3}{*}{45} & \multirow{3}{*}{89} & \multirow{3}{*}{45} \\
\hline 50 & 12 & 56 & 45 & & & \\
\hline 63 & 15 & 71 & 56 & & & \\
\hline 80 & 19 & 90 & 71 & \multirow{3}{*}{88} & \multirow{3}{*}{177} & \multirow{3}{*}{88} \\
\hline 100 & 23 & 112 & 89 & & & \\
\hline 125 & 29 & 140 & 111 & & & \\
\hline 160 & 37 & 180 & 143 & \multirow{3}{*}{177} & \multirow{3}{*}{354} & \multirow{3}{*}{177} \\
\hline 200 & 46 & 224 & 178 & & & \\
\hline 250 & 58 & 281 & 223 & & & \\
\hline 315 & 73 & 354 & 281 & \multirow{3}{*}{354} & \multirow{3}{*}{707} & \multirow{3}{*}{354} \\
\hline 400 & 93 & 449 & 356 & & & \\
\hline 500 & 116 & 561 & 445 & & & \\
\hline 630 & 146 & 707 & 561 & \multirow{3}{*}{707} & \multirow{3}{*}{1411} & \multirow{3}{*}{707} \\
\hline 800 & 185 & 898 & 713 & & & \\
\hline 1000 & 232 & 1122 & 891 & & & \\
\hline 1250 & 289 & 1403 & 1114 & \multirow{3}{*}{1411} & \multirow{3}{*}{2828} & \multirow{3}{*}{1411} \\
\hline 1600 & 371 & 1796 & 1425 & & & \\
\hline 2000 & 463 & 2245 & 1782 & & & \\
\hline 2500 & 579 & 2806 & 2227 & \multirow{3}{*}{2828} & \multirow{3}{*}{5657} & \multirow{3}{*}{2828} \\
\hline 3150 & 729 & 3536 & 2806 & & & \\
\hline 4000 & 926 & 4490 & 3564 & & & \\
\hline 5000 & 1158 & 5612 & 4454 & \multirow{3}{*}{5657} & \multirow{3}{*}{11314} & \multirow{3}{*}{5657} \\
\hline 6300 & 1459 & 7072 & 5613 & & & \\
\hline 8000 & 1835 & 8980 & 7127 & & & \\
\hline 10000 & 2316 & 11225 & 8909 & \multirow{3}{*}{11314} & & \\
\hline 12500 & 2895 & 14031 & 11136 & & 22627 & 11314 \\
\hline 16000 & 3705 & 17959 & 14254 & & & \\
\hline
\end{tabular}

wheels, mileage of the vehicle, the way of braking of the vehicle, material of brake blocks or brake plates and so on.

The calculation of the relation between the frequency and wavelength dependency is processed according to the relation:

$$
\lambda=\frac{V}{f \cdot 3.6} \cdot 100
$$

$\lambda$ is wavelength $(\mathrm{cm})$

$V$ is velocity $(\mathrm{km} / \mathrm{h})$

$f$ is frequency $(\mathrm{Hz})$ 


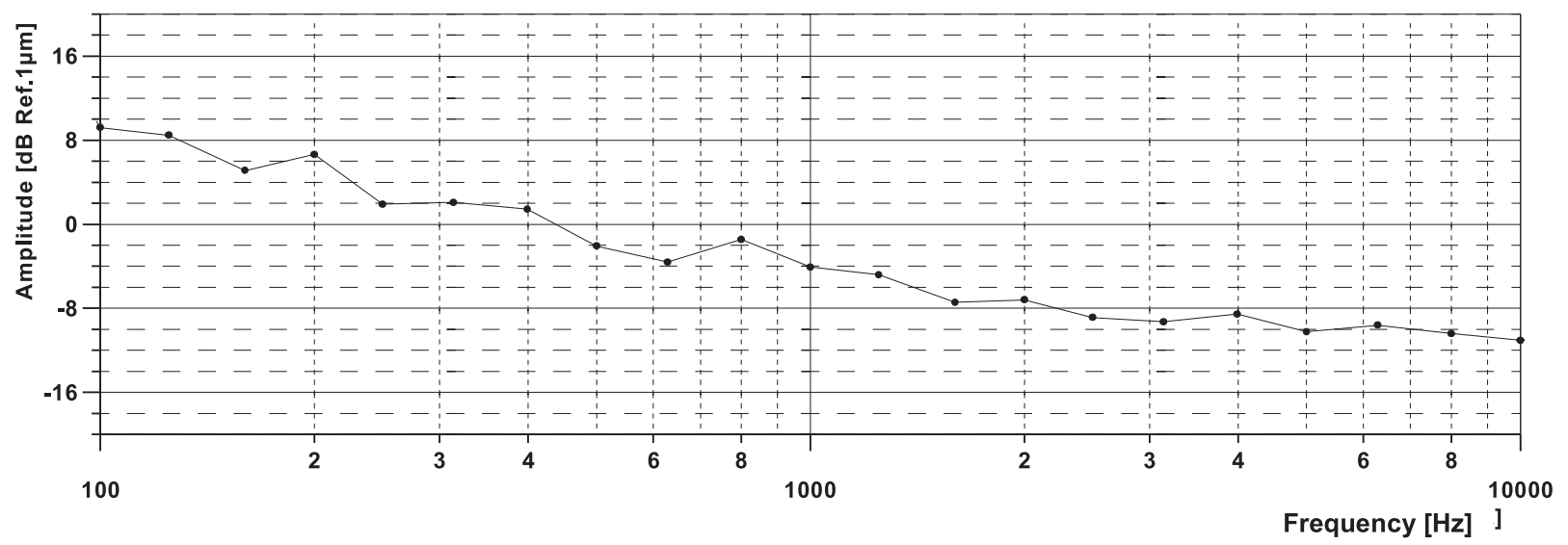

Fig. 8 One-third octave spectrum for unroundness of the wheel, amplitude on a frequency dependency and log. $x$-axis $(V=80 \mathrm{~km} / \mathrm{h})$

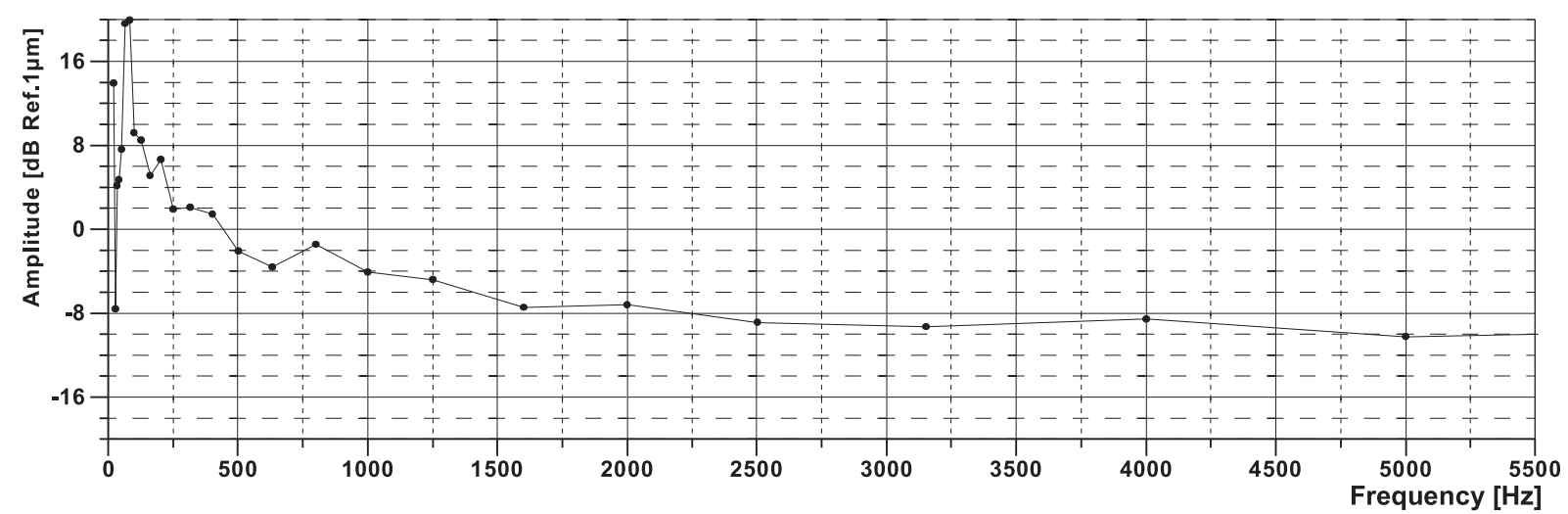

Fig. 9 One-third octave spectrum for unroundness of the wheel, frequency dependency $(V=80 \mathrm{~km} / \mathrm{h})$

\section{One third octave spectrum}

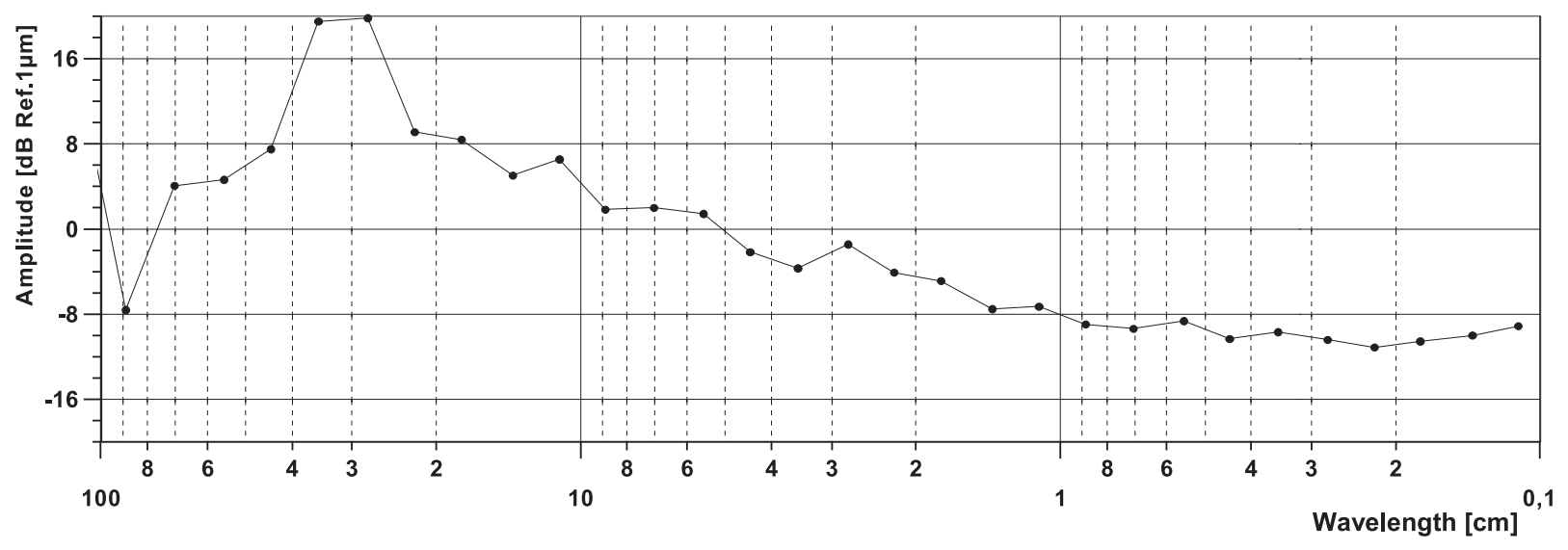

Fig. 10 The one-third octave spectrum for unroundness of the wheel, amplitude on a wavelength dependency $(V=80 \mathrm{~km} / \mathrm{h})$ 


\section{Power spectrum}

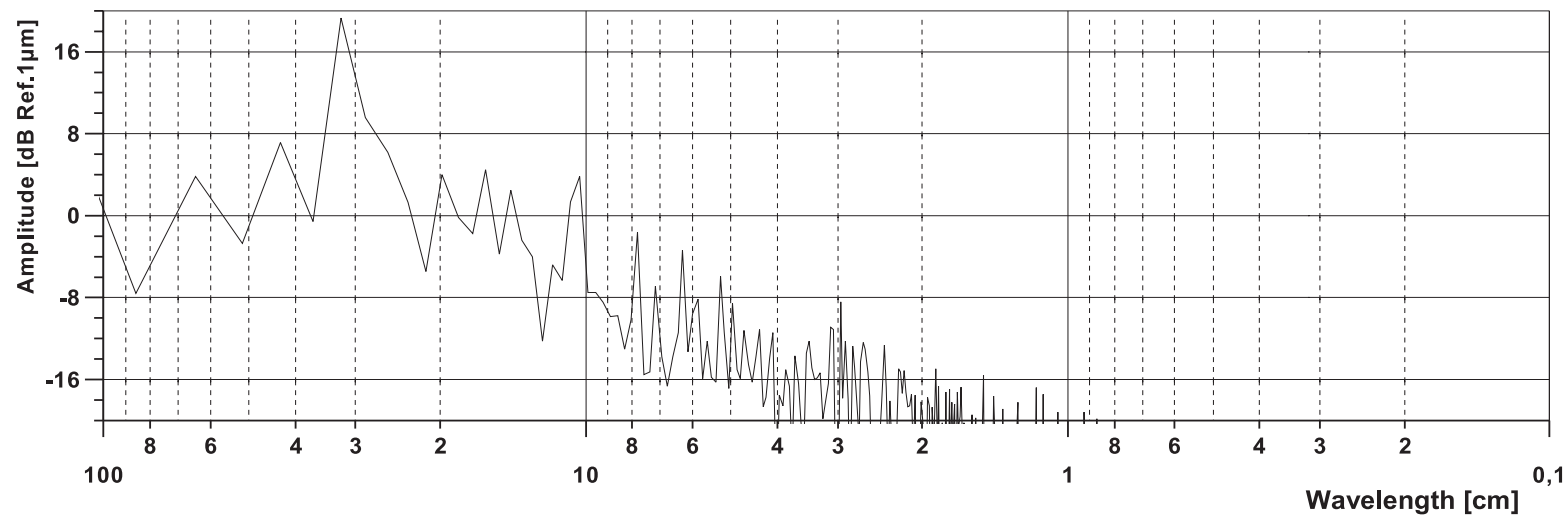

Fig. 11 Power spectrum for unroundness of the wheel, amplitude on a wavelength dependency and log. $x$-axis $(V=80 \mathrm{~km} / \mathrm{h})$

\section{Amplitude spectrum}

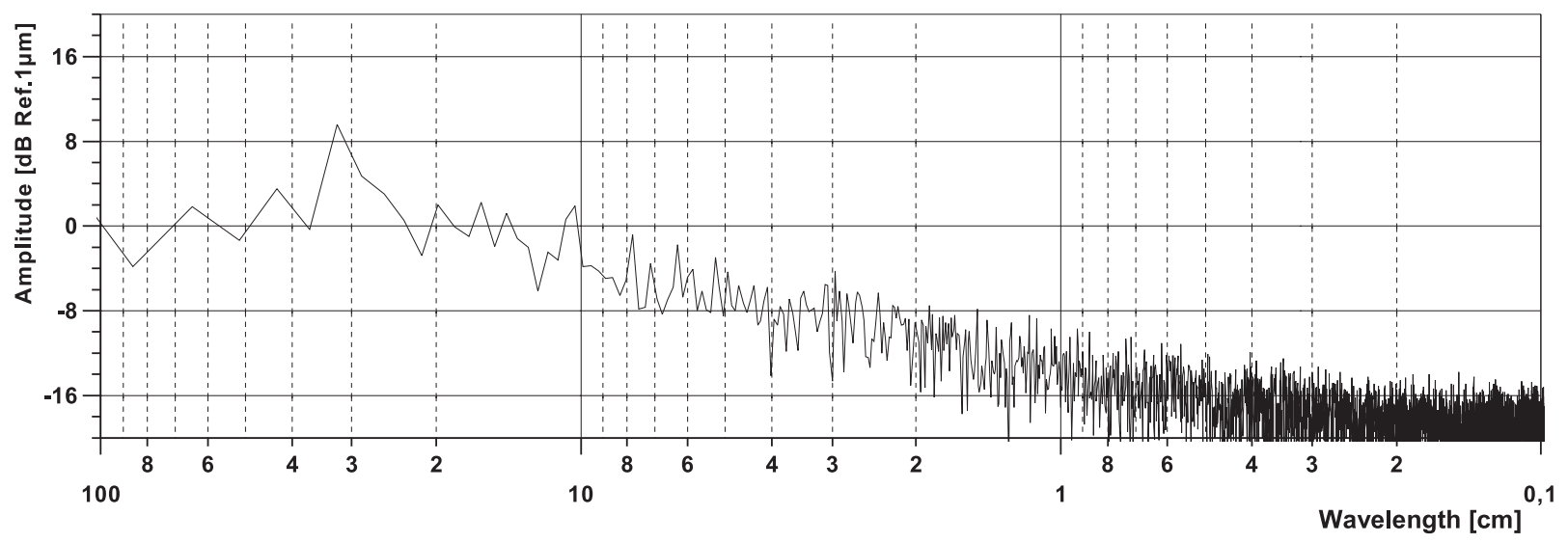

Fig. 12 Amplitude spectrum for unroundness of the wheel, amplitude on a wavelength dependency and log. x-axis

In the figures from 10 to 12 are depicted various dependencies. These graphs can be useful for an unroundness evaluation. There are the one-third octave spectrum for unroundness of the wheel - amplitude on a wavelength dependency, the power spectrum for unroundness of the wheel - amplitude on a wavelength dependency and log. $x$-axis and amplitude spectrum for unroundness of the wheel - amplitude on a wavelength dependency and $\log$. x-axis.

\section{Conclusion}

The imperfection of railway wheel roundness and rail surface roughness cause the generation of vibrations which act not only in the closest distance from the source - wheel/rail contact and the noise is their consequence, but they spread via the rail into track and via the wheel into the vehicle where they act directly as noise and excite vehicle parts which then create noise and moreover, the overall noise increases as a result of the effect of rebounded outside noise from barriers which are in the way of spreading. Out of these issues we analysed chosen issues which are connected with the railway wheel un-roundness and their evaluation on the base of statistical data processing on which Fourier transformation with the help of one third octave analysis was applied.

\section{Acknowledgement}

The work was supported by the Scientific Grant Agency of the Ministry of Education of the Slovak Republic and the Slovak Academy of Sciences in Project No. 1/4119/07: "Investigation of Dynamic Properties of a Vehicle". 


\section{COMMNICOIIIONS}

\section{References}

[1] ERRI B 169/RP 18, Überprüfung des akustischen Verhaltens von neuen Radbauformen. Pr. 4.1, f1/3, 2003

[2] GERLICI, J.: The Contact of a Railway Wheelset and a Track (in Slovak), Habilitation Work, pp. 159, fig. 195. Faculty of Mechanical Engineering University of Žilina, 2004.

[3] JACOBSON, B., KALKER, J. J.: Rolling Contact Phenomena, CISM Courses and Lectures No. 411. Int. Centre for Mechanical Sciences, ISBN- 3-211-83332-3 Springer-Verlag Wien, New York. CISM, Udine, 2000.

[4] LACK, T.: The Dynamic Properties Analysis of Vehicles from the Point of View of Ride Comfort (in Slovak), Habilitation Work, pp. 176, fig. 178, Faculty of Mechanical Engineering University of Zilina, 2007.

[5] prEN ISO 3095, Final Draft 11/2002, Railway Applications - Acoustics - Measurement of Noise Emitted by Railbound Vehicles (ISO/DIS 3095:2001), Brussel 2001. 